\section{Is the Canadian Healthcare System Neglecting a Significant Proportion of the Rheumatoid Arthritis Population?}

\section{To the Editor:}

We read with interest the report by Edworthy and colleagues ${ }^{1}$ which raised the question, Is the Canadian healthcare system neglecting a significant proportion of the rheumatoid arthritis (RA) population? The authors conclude the answer is yes. We agree and feel it is time to begin work towards a national consensus on the optimal management of patients with RA within the framework of the Canadian healthcare system.

Edworthy, et $a l^{1}$ reported on an audit entitled the Assessment in Rheumatology (AIR) program, in which 65 Canadian rheumatologists enrolled 1596 consecutive patients with RA. Patients were seen only once and classified according to 4 states of disease activity: remission, controlled, smoldering, and uncontrolled (Table 1). Participating rheumatologists also recorded current treatments and changes made to the patient's treatment regimen, if any.

Over half the AIR patients had smoldering or uncontrolled disease at the time they were seen and the data on therapy changes are of considerable interest. While $28.7 \%$ of all patients had smoldering disease, more than $40 \%$ of those patients did not have their RA therapy changed.

Particularly notable is that participating rheumatologists stated they did not feel a change of therapy was necessary in almost $30 \%$ of the patients with smoldering disease. In two-thirds of those cases, current therapy was considered acceptable. Other reasons not to change were "not enough time to evaluate current effort," "patient is improving with current therapy," and even "patient has no more signs of disease activity."

There is now a substantial body of evidence that remission can be achieved in a significant proportion of patients with both early and established RA by treating early, treating to target, and optimizing traditional disease-modifying antirheumatic drug (DMARD) and biologic dosing and combinations $^{2-6}$. In the AIR audit program, a large proportion of patients with both uncontrolled and smoldering disease did not have any change in their management - in a significant number of cases because their rheumatologists did not feel a change was necessary.

In light of these findings, several questions must be asked: Are Canadian rheumatologists adequately evaluating their patients with validated outcome measures? Is the concept of treating to a target of remission, or at least of low disease activity, accepted as the norm? We believe the AIR audit program has demonstrated that the answer is, in many cases, no. We believe that the likelihood of patients with RA achieving adequate disease control will increase if their physicians (1) specifically target remission/low disease activity state; (2) regularly assess disease activity, using consistent measures and metrics; (3) recognize inadequate responses, and respond appropriately; and (4) optimize therapy (traditional DMARD and biologic dosing and combinations).

There is a clear need for a national consensus on the optimal management of RA within the framework of the Canadian healthcare system. We propose to begin development of a practical tool to evaluate patients in daily clinical practice. The tool will be evidence-based, practical, and easy to use, in order to facilitate its rapid adoption. It will be developed through a Delphi process, involving rheumatologists from all areas of the country. We believe the iterative structure of the Delphi process will enable participants to achieve a practical consensus based on the realities of medical practice in Canada - and that when implemented, those agreed-upon "best practices" targeting remission will improve the management of patients with RA.

BOULOUS HARAOUI, MD, Université de Montréal, Montreal, Quebec; HANI EL-GABALAWY, MD, University of Manitoba, Winnipeg, Manitoba; MAJED KHRAISHI, MB, Memorial University of Newfoundland, St. John's, Newfoundland; CARTER THORNE, MD, Southlake Regional Health Centre, Newmarket, Ontario, Canada. Address correspondence to Dr. B. Haraoui, CHUM, Hôpital Notre-Dame Rheumatology, Montreal, Quebec. E-mail: bharaoui@videotron.ca

\section{REFERENCES}

1. Edworthy S, Zummer M, Garner S, Boire G, Leclercq S, Bykerk V, et al. Smoldering rheumatoid arthritis: is the Canadian healthcare system neglecting a significant disease population? J Rheumatol 2008;35:1506-12.

2. van der Kooij SM, Goekoop-Ruiterman YP, De Vries-Bouwstra JK, Guler-Yuksel M, Zwinderman AH, Kerstens PJ, et al. Drug-free remission, functioning and radiographic damage after 4 years of response-driven treatment in patients with recent onset rheumatoid arthritis. Ann Rheum Dis 2009;68:914-21.

3. Emery P, Breedveld FC, Hall S, Durez P, Chang DJ, Robertson D, et al. Comparison of methotrexate monotherapy with a combination of methotrexate and etanercept in active, early, moderate to severe rheumatoid arthritis (COMET): a randomised, double-blind, parallel treatment trial. Lancet 2008;372:375-82.

4. Breedveld FC, Weisman MH, Kavanaugh AF, Cohen SB, Pavelka $\mathrm{K}$, van Vollenhoven R, et al. The PREMIER study: A multicenter, randomized, double-blind clinical trial of combination therapy with adalimumab plus methotrexate versus methotrexate alone or adalimumab alone in patients with early, aggressive rheumatoid arthritis who had not had previous methotrexate treatment. Arthritis Rheum 2006;54:26-37.

5. Makinen $\mathrm{H}$, Kautiainen $\mathrm{H}$, Hannonen $\mathrm{P}$, Mottonen $\mathrm{T}$, Leirisalo-Repo M, Laasonen L, et al. Sustained remission and reduced radiographic progression with combination disease modifying antirheumatic drugs in early rheumatoid arthritis. J Rheumatol 2007;134:316-21.

6. Grigor C, Capell H, Stirling A, McMahon AD, Lock P, Vallance R, et al. Effect of a treatment strategy of tight control for rheumatoid arthritis (the TICORA study): a single-blind randomised controlled trial. Lancet 2004;364:263-9.

J Rheumatol 2009;36:12; doi:10.3899/jrheum.090321

Table 1. Assessment In Rheumatology disease state criteria ${ }^{1}$

\begin{tabular}{|c|c|}
\hline Remission & No evidence of disease activity (such as morning stiffness, decreased energy, or active joints) \\
\hline Controlled & $1-2$ active joints ${ }^{\dagger}$, with no morning stiffness or decreased energy \\
\hline Smoldering & $\begin{array}{l}\text { 3-4 active joints }{ }^{\dagger} \text {, with increased morning stiffness, decreased energy level, or elevated } \\
\text { erythrocyte sedimentation rate (ESR) }\end{array}$ \\
\hline controlled & $>4$ active joints ${ }^{\dagger}$, morning stiffness, and decreased energy or elevated ESR \\
\hline
\end{tabular}

$\dagger$ Data collection allowed physicians to indicate only if a particular region was swollen or tender. An active joint region meant that at least 1 joint within a joint region (e.g., metacarpophalangeal joint) was swollen or tender at the time of examination. 